Head drop

\section{Head drop and camptocormia}

\section{T Umapathi, V Chaudhry, D Cornblath, D Drachman, J Griffin, R Kuncl}

\section{The spectrum of bent spine disorders}

$\mathrm{H}$ ead ptosis (drop) results from weakness of the neck extensor, or increased tone of the flexor muscles. It is characterised by marked anterior curvature or angulation of the cervical spine and is associated with various neuromuscular (table 1) and extrapyramidal disorders. ${ }^{12-15}$ Camptocormia or the bent spine syndrome was first described in hysterical soldiers in 1915 by the French neurologist Souques. ${ }^{16}$ Typically there is marked anterior curvature of the thoracolumbar spine. In some patients the spine is angulated forward, the arms propped against the thigh for support. More cases, all among soldiers, were reported during the first and second world wars. These patients responded well to psychotherapy. Recently camptocormia arising as a result of weakness or abnormality in the tone of the paraspinal muscles has been described (table 2). In contrast with other skeletal disorders of the spine such as kyphosis, the deformity in head ptosis and camptocormia is not fixed and is corrected by passive extension or lying in the supine position. It is not possible to straighten the neck or back voluntarily. The evaluation of these disorders can indeed be challenging and often no definite diagnosis is made, as illustrated by four cases of head ptosis and camptocormia seen by us at the Johns Hopkins Hospital.

\section{CASE A}

An 80 year old man developed head ptosis insidiously over a period of few weeks. A week before this he had an upper respiratory tract infection and also experienced transient sharp pain over the left and then the right shoulder. He had no diplopia, dysarthria, dysphagia, limb weakness, or fatiguability. Examination showed severe neck extensor weakness, Medical Research Council (MRC) grade 2. Muscle strength was normal in all other cranial, proximal, and distal limb muscles. Serum creatine kinase (CK) was 362 IU/l (normal 24-195) at presentation. Antiacetylcholine receptor antibody was not detected. Repetitive nerve stimulation of right biceps, right nasalis and right trapezius was normal. A therapeutic trial of pyridostigmine failed. Cervical spine MRI did not show significant compression of the cord, roots, or any specific changes in the paraspinal muscles. An EMG disclosed positive sharp waves restricted to lower cervical paraspinal muscles. To reduce confounding from neuropathic changes secondary to coexistent age related spondylotic changes, the thoracic paraspinal muscle was chosen for biopsy. The pathological findings were mixed. There were neuropathic changes such as angular atrophic fibres;

Table 1 Neuromuscular causes for head ptosis

\begin{tabular}{|c|c|}
\hline Site of pathology & Disorders \\
\hline Motor neuron & $\begin{array}{l}\text { Amyotrophic lateral sclerosis' } 2 \\
\text { Postpolio syndrome }^{3}\end{array}$ \\
\hline Peripheral nerve & Chronic inflammatory polyneuropathy ${ }^{4}$ \\
\hline Neuromuscular junction & Myasthenia gravis' ${ }^{\prime}$ \\
\hline \multirow{7}{*}{$\begin{array}{l}\text { Muscle } \\
\text { (a) Inflammatory } \\
\text { (b) Congenital/hereditary }\end{array}$} & \\
\hline & 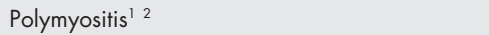 \\
\hline & Inclusion body myositis ${ }^{2}$ \\
\hline & Nemaline myopathy ${ }^{56}$ \\
\hline & Mitochondrial myopathy ${ }^{7}$ \\
\hline & Carnithine deficiency ${ }^{8}$ \\
\hline & Unspecified congenital myopathy ${ }^{9}$ \\
\hline \multirow[t]{4}{*}{ (c) Endocrine/metabolic } & Facioscapulohumeral dystrophy' \\
\hline & Cushing syndrome $^{7}$ \\
\hline & Hypothyroid myopathy ${ }^{10}$ \\
\hline & Myotonic dystrophy with severe hypothyroidism ${ }^{2}$ \\
\hline
\end{tabular}

Table 2 Causes of camptocormia

\begin{tabular}{|c|c|}
\hline & Disorders \\
\hline \multicolumn{2}{|l|}{ Neuromuscular } \\
\hline Motor neuron & $\begin{array}{l}\text { Amyotrophic lateral } \\
\text { sclerosis } 1718\end{array}$ \\
\hline \multirow[t]{3}{*}{ Muscle } & $\mathrm{IBM}^{19}$ \\
\hline & Nemaline myopathy ${ }^{20}$ \\
\hline & $\begin{array}{l}\text { Facioscapulohumeral } \\
\text { dystrophy }\end{array}$ \\
\hline \multirow[t]{4}{*}{ Parkinsonism } & Idiopathic $^{21}$ \\
\hline & Postencephalitic 2223 \\
\hline & $\begin{array}{l}\text { Villiusk } \\
\text { encephalomyelitis }^{24}\end{array}$ \\
\hline & $\begin{array}{l}\text { Sodium valproate } \\
\text { toxicity }{ }^{25}\end{array}$ \\
\hline Idiopathic & \\
\hline
\end{tabular}

occasional nuclear sacs, target and targetoid fibres as well as myopathic features such as the presence of hypertrophic and split muscle fibres; a few necrotic, degenerating and regenerating fibres; increased internalised nuclei, and mild endomysial fibrosis. No type grouping was noted, but there was massive type I predominance. No specific treatment was offered. A few months later, he started to improve. At follow up 2 years later, he was able to keep his head up for prolonged periods, especially in the sitting position. However, he was more symptomatic while standing. He reported an overall $60 \%$ subjective improvement in neck strength and weakness had not progressed to other muscles.

\section{CASE B}

A 74 year old man with diabetes mellitus and hyperlipidaemia (for which he had been taking a statin for a few years) complained of progressive anterior curvature of the spine associated with proximal limb weakness for few months. On examination, he had moderately severe anterior thoracolumbar curvature that could be extended passively. Diffuse weakness was present; proximal limb strength was MRC grade 4 and distal, 4+. Electrodiagnostic evaluation only showed evidence of an axonal polyneuropathy, consistent with diabetes. Serum CK was persistently raised (367 IU/1). Spine MRI only showed mild degenerative changes. Anti-acetylcholine receptor antibody was not detected. Biopsy of the rectus femoris showed increased fibre size variability, necrosis, mild fibrosis, occasional red rimmed vacuoles, and one fibre which stained positive for ubiquitin, suggestive of inclusion body myositis. However, inflammation or amyloid

Abbreviations: CK, creatine kinase; MSA, multisystem atrophy; ALS, amyotrophic lateral sclerosis 
deposition were not seen. Despite stopping statin, his weakness continues to progress and $\mathrm{CK}$ has remained raised (239 IU/L).

\section{CASE C}

A 59 year old woman presented with a 4 year history of progressive, painless anterior curvature of the spine. She had a family history of facioscapulohumeral muscular dystrophy but not of bent spine. Examination showed camptocormia along with scapular winging and mild facial and proximal weakness. Her CK was at the upper limit of normal, 186 IU/l. An EMG showed short duration, small amplitude motor units with early recruitment in the proximal muscles. Abnormal spontaneous activity was seen in the thoracic paraspinal muscles. No decremental response to repetitive nerve stimulation was present. Spine MRI was unremarkable. 4q35 gene deletion, consistent with facioscapulohumeral muscular dystrophy, was detected.

\section{CASE D}

A 63 year old woman developed slowly progressive, painless thoracolumbar stoop of about 30 degrees over 8 to 9 years. The deformity was not fixed and was worse in the standing position, better sitting, and minimal while lying down. There was no family history of similar weakness. She had been taking lipid lowering drugs for 10 years and symptoms did not improve on their withdrawal. Weakness was demonstrable in the thoracic paraspinal and proximal limb muscles. Her CK was persistently raised at 606 IU/l (after withdrawal of atorvastatin for 6 months). Antiacetylcholine receptor antibody was not detected. Spinal MRI showed mild degenerative changes in the cervical spine and normal thoracic spine. No specific changes were seen in the paraspinal muscles. Spontaneous activity consisting of positive sharp waves, fibrillation potentials, and complex repetitive discharges were only seen in the right lower cervical paraspinal muscles. Biopsy of the rectus femoris muscle disclosed rare necrotic and regenerating fibres, mild increase in fibre size variability, internal nuclei and minimal fibre type grouping. No specific diagnosis on the type of myopathy could be made. Although she subjectively felt slightly subjectively worse at a review 9 months later there was little change to her condition.

\section{HEAD DROP}

Table 1 shows the various neuromuscular disorders reported to cause head ptosis. Myasthenia gravis, especially in elderly people ${ }^{26}$ and amyotrophic lateral sclerosis are the commonest causes. The predilection of these diseases for focal or segmental onset may explain this. Severe isolated antecollis causing forced anteroflexion of the neck occurs in parkinsonian syndromes. Rivest et al have documented antecollis in four of their necropsy proved cases of multisystem atrophy (MSA). ${ }^{12}$ The abnormality develops, sometimes in a subacute manner over a period of weeks, in the late or middle stages of the disease. The neck can only be passively and forcibly extended to its normal position with difficulty. None of the patients had convincing dystonic spasms of the anterior neck muscles, although deeper muscles may be involved. Speech, swallowing, and upgaze deficits are often associated. Trials of botulinum toxin into both sternocleidomastoid muscles are ineffective and response to levodopa generally disappointing. ${ }^{12}{ }^{13}$ Earlier case reports have also documented the association between MSA and head drop..$^{27-29}$

Yoshiyama et $a l^{14}$ published a series of seven patients with parkinsonism exhibiting head drop, four of whom carried a diagnosis of probable MSA. Although at rest there was no anterior neck spasm, attempts to extend the head voluntarily or passively was accompanied by contraction of the sternocleidomastoid muscles on surface EMG in all of these patients. There was no correlation between the severity of the head ptosis and parkinsonism. Three patients had improvement of neck symptoms with treatment of parkinsonism, whereas one worsened. A recent report described head ptosis in seven out of 459 patients evaluated for parkinsonism. ${ }^{15}$ All seven had features of MSA. Interestingly these patients were also documented to have weakness as well as electrophysiolgical and pathological features of myopathy in the neck extensor muscles. Okamiya et al reported a patient with vascular parkinsonism and neck extension weakness who had myopathic changes in the extensor muscles. ${ }^{30}$ One of our patients (listed $\mathrm{JHH}$ case 2 in table 3 ), who has some clinical evidence of MSA, showed mixed myopathic and neurogenic features in the paraspinal muscles.

\section{IDIOPATHIC HEAD DROP}

In some cases, no obvious aetiology for the head drop is apparent even after extensive evaluation and on prolonged follow up. ${ }^{21-33}$ Combining the data from various reports of idiopathic head ptosis in the literature and patients seen at our institution (table 3), the following profile of idiopathic head ptosis emerges. The female to male ratio is $3: 2$. Mean and median ages at presentation are 74.5 and 73 respectively. The onset is often subacute, over days and weeks rather than months. Two of our patients and one that was reported by Lerman ${ }^{33}$ had a history of significant weight loss. Discomfort at the back of the neck is reported in some patients but other sensory abnormalities are not prominent. The weakness is profound in the neck extensors, and involvement of contiguous proximal muscles is at most modest. The CK was normal in all but two patients. Katz at $a l^{2}$ reported oedema-like changes and atrophy of the neck extensor muscles on MRI. An EMG of the paraspinal muscles was remarkable for the increased reports of spontaneous activity. Fibrillations were present in nine and positive sharp waves in one out of the 15 patients for whom EMG data are available. Interestingly, such abnormalities were pronounced in the lower cervical segments; and in one case reported by Katz et al, ${ }^{2}$ extended to the midthoracic region. The motor unit action potentials in most cases are described as having short duration and small amplitude with early recruitment. However, this has to be interpreted with caution as paraspinal motor unit action potentials are generally small and may have multiple turns even in normal individuals. EMG of the limb muscles is mostly unremarkable. The histology of limb muscles is normal or reveals mild non-specific myopathic changes such as increased fibre size variability. In two of our cases there is some evidence of denervation. The paraspinal muscle biopsies show less subtle but again non-specific changes such as fibrosis, increased fibre size variability, "moth eaten" fibres, and myofibrillar disarray. Degeneration, regeneration, and necrosis were reported by Jaster $e t a l^{32}$ and also seen in one of our patients. Interestingly, as mentoned above, similar biopsy findings have been reported in the neck extensor muscles of patients with parkinsonism who also have head drop, ${ }^{15}{ }^{30}$ suggesting that these changes may not be specific for a neuromuscular disorder.

The weakness remains localised and in most cases stabilises after a short period of progression. In some patients (including our case A) there is some documented recovery. Secondary skeletal deformity can result in disability even after good recovery of neck strength, ${ }^{32}$ highlighting the importance of maintaining good neck posture during the period of weakness. Immunosuppressive agents have been tried for varying periods with disappointing results overall. Rose et $a l^{7}$ reported a positive effect with prolonged corticosteroids, but their patient had generalised weakness and inflammatory infiltrates (albeit scanty) in one biopsy. There may be a role for cervical spine fusion in allowing patients with disabling and nonrecovering head drop to maintain a functionally useful head position.

\section{Camptocormia}

The causes of camptocormia are summarised in table 2. As in head drop, several 


\begin{tabular}{|c|c|c|c|c|c|c|c|c|c|c|c|}
\hline \multirow[b]{2}{*}{ Report } & \multirow[b]{2}{*}{ Sex } & \multirow{2}{*}{$\begin{array}{l}\text { Onset } \\
\text { age }\end{array}$} & \multicolumn{2}{|l|}{ Weakness } & \multirow{2}{*}{$\begin{array}{l}\mathrm{CK} \\
\mathrm{IU} / \mathrm{I}\end{array}$} & \multirow[b]{2}{*}{ Paraspinal mus EMG } & \multirow[b]{2}{*}{ Limb EMG } & \multirow[b]{2}{*}{$\mathrm{Cx}$ (cervical) paraspinal bx } & \multirow[b]{2}{*}{ Limb mus bx } & \multirow{2}{*}{$\begin{array}{l}\text { Radiological } \\
\text { examination Cx } \\
\text { (cervical spine) }\end{array}$} & \multirow[b]{2}{*}{ Outcome } \\
\hline & & & At onset & Pattern & & & & & & & \\
\hline $\begin{array}{l}\text { Lange' }^{\prime}(3 \\
\text { patients) }\end{array}$ & - & - & - & - & - & - & - & ${ }^{*}$ Non-diagnostic & ${ }^{*}$ Non-diagnostic & - & Unchanged $3-5$ y \\
\hline $\begin{array}{l}\text { Suarez } z^{31} \\
\text { case } 1\end{array}$ & M & 71 & 2 months & Mild shoulder weakness & $\mathrm{N}$ & $\begin{array}{l}\text { Fibs, small amp, short } \\
\text { duration MUAP; early rec. at } \\
\text { lower } C x\end{array}$ & - & $\mathrm{N}$ & $\begin{array}{l}\text { Biceps: } \uparrow \text { fibre size } \\
\text { variability }\end{array}$ & Degen & Unchanged 5 months \\
\hline 2 & $\mathrm{~F}$ & 81 & 3 months & $\begin{array}{l}\text { Mild deltoid, neck flexor } \\
\text { weakness }\end{array}$ & $\mathrm{N}$ & $\begin{array}{l}\text { Fibs, small amp, short } \\
\text { duration polyphasic MUAP at } \\
C_{x}\end{array}$ & - & - & $\begin{array}{l}\text { Deltoid: type II } \\
\text { atrophy }\end{array}$ & $\mathrm{N}$ & \\
\hline 3 & $\mathrm{~F}$ & 68 & 3 months & Mild weakness & $\mathrm{N}$ & $\begin{array}{l}\text { Fibs, small MUAP; early rec at } \\
\text { lower } C_{x}\end{array}$ & $\begin{array}{l}\text { Early rec, } \\
\text { sternomastoid } \\
\text { mus }\end{array}$ & $\begin{array}{l}\text { Fibre size variability; NADH: } \\
\text { moth-eaten; GT: } 2 \text { fibres with } \\
\text { vacuoles }\end{array}$ & - & $\mathrm{N}$ & \\
\hline 4 & $\mathrm{~F}$ & 63 & $\begin{array}{l}\text { several } \\
\text { months }\end{array}$ & Mild deltoid weakness & 192 & $\begin{array}{l}\text { Fibs, short duration MUAP; } \\
\text { early rec at } C x \text { and Th }\end{array}$ & - & - & Biceps: type II atrophy & $\mathrm{N}$ & \\
\hline $\begin{array}{l}\text { Katz }^{2} \text { case } \\
1\end{array}$ & $\mathrm{~F}$ & 85 & 6 weeks & $\begin{array}{l}\text { Mild neck flexion and } \\
\text { deltoid weakness }\end{array}$ & $\mathrm{N}$ & $\begin{array}{l}\text { Fibs, short duration MUAP; } \\
\text { early rec at lower Cx to } \\
\text { mid-Th }\end{array}$ & $\mathrm{N}$ & $\begin{array}{l}\text { Fibre size variability, } \uparrow \\
\text { internal nuclei and fibrosis }\end{array}$ & Deltoid: N & $\begin{array}{l}\text { Mild spondyosis, no } \\
\text { neural impingement }\end{array}$ & Unchanged 6 months \\
\hline 2 & M & 64 & 1 week & Nil & $\mathrm{N}$ & $\begin{array}{l}\text { Fibs, short duration MUAP; } \\
\text { early rec. at lower } C x \text { to Th } 1\end{array}$ & $\mathrm{~N}$ & $\begin{array}{l}\text { Fibre size variability, split } \\
\text { fibres; } \uparrow \text { internal nuclei and }\end{array}$ & Biceps: N & $"$ & Unchanged 20 months \\
\hline 3 & $\mathrm{~F}$ & 84 & 3 months & Nil & $\mathrm{N}$ & & $\mathrm{N}$ & $\begin{array}{l}\text { fibrosis, myofibrillar disarray } \\
\text { in hypertrophic fibres }\end{array}$ & Biceps: N & $"$ & Unchanged 54 months \\
\hline 4 & M & 65 & 2 months & Nil & $\mathrm{N}$ & & $\mathrm{N}$ & $\begin{array}{l}\text { As above and } \downarrow \text { central } \\
\text { NADH staining. }\end{array}$ & Deltoid: N & $"$ & Unchanged 48 months \\
\hline Khella ${ }^{34}$ & $\mathrm{~F}$ & 84 & - & Nil & $\mathrm{N}$ & $\begin{array}{l}\text { Short duration, polyphasic } \\
\text { MUAP, early rec }\end{array}$ & - & - & - & - & Stable after $5 y$ \\
\hline Jaster $^{32}$ & M & 69 & $4 \mathrm{~h}$ & Nil & $\mathrm{N}$ & $\begin{array}{l}\text { Small amp, short duration } \\
\text { MUAP at lower } C x\end{array}$ & $\mathrm{~N}$ & $\begin{array}{l}\text { Degen, regen, and necrotic } \\
\text { fibres }\end{array}$ & - & $\mathrm{N}$ & Improves after 6 months \\
\hline $\mathrm{JHH}$, case 1 & M & 80 & 3 weeks & Nil & 362 & PSW in $C \times 5$ and $C \times 8$ & $\mathrm{~N}$ & $\begin{array}{l}\text { Neurogenic and some } \\
\text { myopathic changes }\end{array}$ & - & $\mathrm{N}$ & Improves after 12 months \\
\hline 2 & M & 79 & $1-2$ days & $\begin{array}{l}\text { Mild weakness of neck } \\
\text { flexion and shoulder } \\
\text { abduction }\end{array}$ & $\mathrm{N}$ & $\begin{array}{l}\text { Small amp, short duration } \\
\text { MUAP, early rec at } C x 7-C x \\
8\end{array}$ & $\begin{array}{l}\text { Small amp, short } \\
\text { duration MUAP }\end{array}$ & Neurogenic changes & $\begin{array}{l}\text { Biceps: neurogenic } \\
\text { changes }\end{array}$ & Multilevel degen & $\begin{array}{l}\text { Improves after } 12 \text { months; } \\
\text { has some features of MSA }\end{array}$ \\
\hline 3 & $\mathrm{~F}$ & 81 & "Days" & Mild ptosis & $\mathrm{N}$ & $1+$ fibs, PSW & $\mathrm{N}$ & - & Deltoid: N & Mild degen & $\begin{array}{l}\text { Remains the same } 4 y \\
\text { later }\end{array}$ \\
\hline 4 & $\mathrm{~F}$ & 70 & $\begin{array}{l}\text { "Days"; pain } \\
\text { at onset }\end{array}$ & Mild proximal weakness & $\mathrm{N}$ & $\mathrm{N}$ & $\begin{array}{l}\text { Few small amp, } \\
\text { short duration } \\
\text { MUAP }\end{array}$ & $\begin{array}{l}\text { Non-specific myopathic } \\
\text { changes }\end{array}$ & $\begin{array}{l}\text { Quadriceps: mild } \\
\text { neurogenic changes, } \\
\text { type II atrophy }\end{array}$ & $N$ & $\begin{array}{l}\text { Remains the same } 4 y \\
\text { later }\end{array}$ \\
\hline 5 & $\mathrm{~F}$ & 73 & "Weeks" & Nil & $\mathrm{N}$ & $\begin{array}{l}\text { Small amp, short duration } \\
\text { MUAP; early rec }\end{array}$ & $\mathrm{N}$ & - & $\begin{array}{l}\text { Trapezius: type II } \\
\text { atrophy }\end{array}$ & - & $\begin{array}{l}\text { Remains the same } 4 \text { y } \\
\text { later }\end{array}$ \\
\hline
\end{tabular}

Table 3 Reports on idiopathic head drop 
neuromuscular diseases can present with segmental involvement of the postural muscles, resulting in camptocormia.

\section{Amyotrophic lateral sclerosis (ALS)}

The kyphoscoliotic posture along with head drop is typical in patients with moderately advanced ALS. Involvement of paraspinal muscles was described by Gower in his account of patients with ALS, ${ }^{17}$ "In most cases the wasting involves the muscles of the back, and it sometimes begins in them". Our group had previously reported a patient with ALS who developed severe camptocormia, requiring him to support himself with hands on his thighs. Limb muscles were less involved in this patient. ${ }^{18}$

\section{Myopathy}

Most generalised myopathies, because of pelvic girdle weakness, cause lumbar lordosis rather than kyphosis. The exception may be inclusion body myositis (IBM), This was reported as a cause of erector spinae weakness by Hund et al. ${ }^{19}$ A 70 year old man developed back and later leg weakness over a period of months. The CK was slightly raised. An EMG showed spontaneous activity and polyphasic motor units with reduced recruitment in the paraspinal muscles. A biopsy of a relatively non-atrophic part of the paraspinal muscles was reported to show morphology typical of IBM. The predisposition for focal muscle weakness may explain the occurrence of camptocormia in IBM. Alternatively it may occur as a secondary phenomenon. The preferential weakness of the quadriceps over the iliopsoas often forces the patient to lock the knee in extension and predisposes to a bent over posture for better balance. This may stretch the back muscles excessively, putting them in a position of mechanical disadvantage and in turn lead to further bending. Katz et al has proposed an important role for mechanical factors in the evolution of head drop. ${ }^{2}$ A similar pathophysiology may cause camptocormia in IBM. Nemaline myopathy involves the paravertebral muscles and can cause kyphoscoliosis or lordosis. ${ }^{35}$ This congenital myopathy can rarely present in adult life. A case of a 62 year old woman with adult onset nemaline myopathy who presented with severe camptocormia has been reported. ${ }^{20}$ Furthermore, nearly half the cases of adult onset nemaline myopathy in the literature have been associated with head drop. ${ }^{5}$ We think that facioscapulohumeral muscular dystrophy has not been previously reported as a cause of camptocormia (case C). Interestingly in the series of Lange et al on head ptosis there was one patient with facioscapulohumeral muscular dystrophy. ${ }^{1}$ In the series of Serratrice et al ${ }^{36}$ one patient had type I predominance (in quadriceps/ deltoid muscle biopsy) and fingerprint morphology on ultrastructure, suggestive of a congenital myopathy.

\section{Extrapyramidal disorders}

A mild stooped posture is a hallmark of parkinsonism, but severe anterior curvature is not common. Djaldetti et al ${ }^{21}$ described eight patients with presumed idiopathic Parkinson's disease, at Hoehn

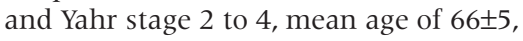
and symptom-duration of $13.1 \pm 5.1$ years who had severe forward flexion of the thoracolumbar spine. This was apparent on standing, less obvious while sitting, but disappeared in the supine position. There was no mention of the nature of onset. The EMGs of the paraspinal muscles done in five patients were normal. Three patients apparently had immediate and reversible aggravation of the bent spine with levodopa therapy whereas the others improved. The authors postulated that camptocormia in parkinson's disease may represent a type of dystonia.

Postencephalitic parkinsonism has also been reported to cause curvature of the spine. Onuaguluchi ${ }^{22}$ reported five cases in 1964, followed a year later by a series consisting of 14 cases from Martin. ${ }^{23} 37$ The latter included seven photo illustrated case histories. The spinal curvature in these patients was in both anteroposterior as well as lateral planes and diminished in the supine position. In many patients it was noted to extend "from sacrum to neck". In one woman the forward flexion of the neck was only seen when she was blindfolded. There was no consistent relation of the spinal curvature to the side of greater muscular rigidity. Three patients underwent stereotactic surgery. One patient received lesions to the ventrolateral thalamus and pallidum and another to the pallidum alone, ipsilateral to the concavity of the spine. A third patient received a lesion to the pallidum contralateral to the side of spinal curvature. In all the cases rigidity and tremor on the opposite side was abolished; but the spinal curvature was corrected only in the cases where the stereotactic lesion was placed ipsilateral to the concavity of the spinal curvature. Animal work by Ferrier, ${ }^{38}$ Demas-Marsalet ${ }^{39}$ and Hassler ${ }^{40}$ had previously shown that unilateral caudate lesions could cause a similar deformity of the spine in animals, which can be corrected by destruction of the contralateral head of the caudate nucleus. Severe pathological changes have been described in the caudate nucleus in postencephalitic parkinsonism. ${ }^{41}$ Martin hypothesised that tonic activity in the caudate nuclei and its efferent pathways to the pallidum might play an important part in maintaining spinal posture. ${ }^{41}$

The slowly progressive and chronic forms of a rare encephalomyelitis that occurs among the Lakut people of Siberia, termed Viliuisk encephalomyelitis, ${ }^{24}$ is also characterised by a forward bent posture. Other features include rigidity, bradykinesia, dementia, and dysarthria. Pathological findings include multiple areas of inflammation, necrosis, perivascular leucocytic cuffing, spongiform changes, and fibrosis as well as marked atrophy of the basal ganglia. ${ }^{24}$

Camptocormia was reported as a side effect of sodium valproate toxicity in a 23 year old epileptic patient. ${ }^{25}$ Interestingly the deformity resolved when the plasma valproate level dropped to about 300 $\mu \mathrm{mol} / \mathrm{l}$, only to return 4 months later when the plasma concentration rose to about 330-530 $\mu \mathrm{mol} / \mathrm{l}$. This patient had no other extrapyramidal features. Reversible parkinsonism has been well documented as a rare side effect of valproate $^{42} 43$ and an extrapyramidal mechanism might have been responsible for the effect of valproate on spinal posture.

\section{IDIOPATHIC CAMPTOCORMIA}

In some cases of camptocormia, such as head ptosis, the clinical abnormality remains confined to the back and no apparent cause is found even on prolonged follow up. ${ }^{163644-47}$ Is idiopathic camptocormia a distinct entity? Table 4 summarises the various reports on this condition. The data from these studies were combined with our cases B and D to develop a profile of idiopathic camptocormia. The incidence of camptocormia, like head drop, increases with advancing age. All but eight patients developed it at an age older than 60 . The earliest age of onset is 49 years. The female to male ratio is about $3: 1$. The weakness is mainly confined to the extensor muscles of the spine. Onset and progression are more chronic compared with head drop, often extending over a period of months to years. Mild back discomfort was present in a few. Sensory symptoms were absent. The presence of a family history in some patients ${ }^{36}{ }^{46}$ suggests that investigations for genetic and congenital neuromuscular conditions such as facioscapulohumeral muscular dystrophy and nemaline myopathy may result in better characterisation of the idiopathic cases. The CK is raised in cases $\mathrm{B}$ and $\mathrm{D}$ and in some of the cases described by Hilliquin et $a l^{48}$ and Serratice et al. ${ }^{36}$ The paraspinal muscles have been reported to show atrophy and a heterogenous appearance on radiological examination (CT or MRI). The EMG findings are not uniform, with reports of both myogenic and neurogenic features. In case D, spontaneous activity consisting of positive sharp waves, fibrillation potentials, and complex repetitive discharges is seen only in the right lower cervical paraspinal muscles, probably an incidental finding. 


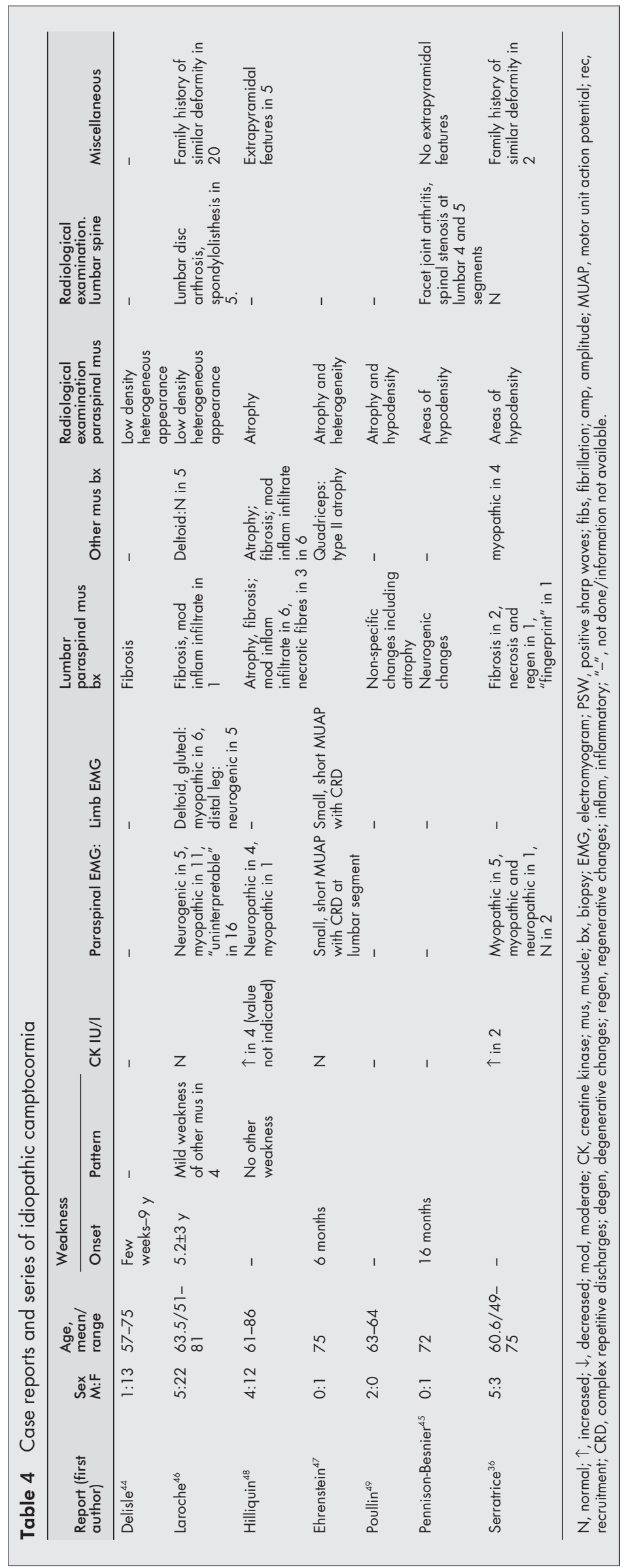

Ehrenstein reported complex repetitive discharges in the lumbar paraspinal and limb muscles in his single case report. ${ }^{47}$ The paraspinal muscle biopsy findings are generally myopathic with increased fibrosis, variation in fibre size, and atrophy. Limb muscle histology is variable and no definite pattern was discernible. Cases B and D had necrotic muscle fibres, and the former rimmed vacuoles, but no specific diagnosis could be made. Information on therapeutic options is sparse and difficult to interpret. ${ }^{16} 4748$ Some authors have reported dramatic recovery with intravenous methylprednisolone. ${ }^{48}$ The early use of corsets and other forms of spinal support may be useful to prevent the formation of fixed secondary deformities.

Idiopathic head ptosis and

camptocormia: possible pathophysiological factors

Head ptosis and camptocormia are age related disorders

Idiopathic head ptosis and camptocormia occur mainly in those beyond the age of 60 and are almost never seen at ages less than 50 years. It seems that the age at presentation of head ptosis and camptocormia is advanced even in patients with an underlying disorder. In a recent study of 10 elderly patients with myasthenia gravis, age range $80-88$ years, head drop was the commonest presentation, occurring in six patients. ${ }^{26}$ By contrast, ptosis was the presenting complaint in only three patients. ${ }^{26} \mathrm{Nema-}$ line myopathy in childhood is associated with spinal abnormalities such as rigidity, scoliosis, and lumbar lordosis. However, in adult onset cases campocormia ${ }^{20}$ and a high incidence of head ptosis ${ }^{56}$ have been reported.

Katz et $a l^{2}$ have proposed that in elderly people, age related loss of tissue elasticity and mild kyphosis ${ }^{50}$ predisposes to chronic stretch injury of paraspinal muscles and may contribute to the development of head ptosis. Similar factors may be involved in the pathogenesis of idiopathic camptocormia. As discussed above, some of the reported histological changes in the paraspinal muscles of patients with idiopathic head ptosis were also seen in those with an obvious extrapyramidal cause, ${ }^{15}{ }^{30}$ suggesting that these changes may be non-specific changes, resulting from chronic mechanical strain rather than a specific myopathic disorder. Furthermore, in a study comparing the cervical paraspinal muscle morphology in patients with cervical myelopathies and normal necropsy controls, necrosis, coretargetoid changes, type II atrophy, and type I predominance were seen in both groups with similar prevalence and severity. ${ }^{51}$ The pathological abnormalities were more common and severe with 
Table 5 Similarities and differences between head ptosis and camptocormia

\begin{tabular}{|c|c|c|}
\hline & Similarities & Differences \\
\hline Clinical features & $\begin{array}{l}\text { Advanced age } \\
\text { In some extrapyramidal disorders both can occur in the same patient }{ }^{23}\end{array}$ & $\begin{array}{l}\text { Head ptosis often subacute in onset, while } \\
\text { camptocormia tends to be insidious }\end{array}$ \\
\hline Underlying disorders & Similar neuromuscular and extrapyramidal causes & $\begin{array}{l}\text { Camptocormia is more often associated with } \\
\text { myopathic rather than neurogenic disorders }\end{array}$ \\
\hline $\begin{array}{l}\text { Paraspinal muscle pathology } \\
\text { Prognosis/Outcome }\end{array}$ & $\begin{array}{l}\text { Mixed myopathic and neuropathic features } \\
\text { Improvement and worsening with levodopa therapy has been reported in } \\
\text { parkinsonian patients with head drop as well as camptocormia }{ }^{1421}\end{array}$ & $\begin{array}{l}\text { Camptocormia tends to be progressive with } \\
\text { no reports of spontaneous improvement }\end{array}$ \\
\hline
\end{tabular}

increasing age of patients in disease and control biopsies. ${ }^{51}$ Hence, it may be difficult to make a specific aetiological diagnosis by studying the paraspinal muscles alone.

Probable neuropathic contribution to the pathophysiology of idiopathic head drop and camptocormia

Pennison-Besnier et $a l^{45}$ described a 72 year old woman with a 16 month history of camptocormia, whose lumbar paravertebral muscle showed fibrosis, fatty infiltration of interfascicular septa, groups of angular atrophic fibres, nuclear bags, fibre type grouping on ATPase stain, core, and target fibres. They think that denervation of the paraspinal muscles from impingement of the dorsal rami by osteoarthritic facet joints causes camptocormia. They asserted that the paraspinal muscle biopsies of other reports and two of their patients might not have shown typical neurogenic changes because they were performed late in the course of the illness. However, as already mentioned, neurogenic changes on muscle biopsy are common in elderly people and may not be clinically significant. ${ }^{5152}$ This is especially true in the cervical and lumbar paraspinal muscles, where there is a high incidence of degenerative vertebral disease in elderly people. Furthermore, to cause significant weakness of spinal extension large segments of the paraspinal muscles need to be denervated as sectioning of C1-C6 dorsal branches in patients with spasmodic torticollis ${ }^{53}$ does not cause any functional impairment. In addition, although spondylosis could conceivably damage neural elements by vascular compromise, either from arterial ischaemia at the watershed region of the spinal arteries of Adamkiewicz or venous congestion, direct impingement of spinal roots have not been reported in patients with idiopathic head ptosis and camptocormia (tables 3 and 4). Therefore it is more likely that chronic denervation of the paraspinal muscles is a contributing factor rather than the basis for the development of idiopathic head ptosis and camptocormia.

The presence of pain, relatively acute onset, and recovery of head drop over a period of weeks in some patients is reminiscent of the clinical course of brachial neuritis (Parsonage-Turner syndrome). Indeed the clinical diversity of this condition has been well documented, ${ }^{54} 55$ including involvement of structures as proximal as the roots. Kidron et al had reported C6 root involvement with paraspinal denervation. ${ }^{56}$ Whether a similar process can selectively involve the cervical plexus and the dorsal spinal nerves can only be confirmed by studying the histology of paraspinal muscles and dorsal spinal nerves early in the course of the illness.

\section{HEAD PTOSIS AND CAMPTOCORMIA: PARTS OF A SPECTRUM?}

In most instances head drop and camptocormia are not related. It is rare to find a patient with both disorders except in extrapyramidal disorders such as MSA and postencephalitic parkinsonism. ${ }^{2}$ However, the similarities between them (table 5) suggest that both head ptosis and camptocormia may occur as a result of similar pathophysiological processes affecting paraspinal muscles of different parts of the spine. In any individual patient local factors such as chronic denervation and loss of tissue elasticity may determine the spinal segment involved.

In summary, head ptosis and camptocormia include a diverse group of disorders that share in common involvement of different parts of the spine resulting in disabling anterior curvature of the spine. In addition to the known causes of flexion deformity of the spine, such as myasthenia gravis, amyotrophic lateral sclerosis, and Parkinson's disease, multiple cumulative age related factors such as loss of muscle tone, tissue elasticity, chronic stretch and denervation of the paraspinal muscles from degenerative spinal disease, may be involved in the pathogenesis. In practice, neuromuscular and extrapyramidal disorders, because of therapeutic and prognostic implications, should be ruled out in all patients. Measures to prevent fixed deformities-for example, passive mobilisation of the spine and the use of supports such as corsets and stiff collars—should be instituted early. At least some patients with idiopathic head drop recover partial function spontaneously. There is no clearly defined role for immunosuppressive or other pharmacotherapy. The case report of valproate induced reversible camptocormia introduces the intriguing possibility of using a GABA agonist in cases with an apparent extrapyramidal aetiology. Patients whose head ptosis does not improve should be considered for cervical fusion, which allows the patient to maintain a functionally useful head position.

\section{ACKNOWLEDGEMENTS}

We thank Dr R Kurtzke, Fairfax, Virginia for providing us with information on his patient and valuable comments, and Dr M P T Lunn, Guy's, St Thomas', and King's School of Medicine, London, for contributing important ideas.

Competing interests: none declared

J Neurol Neurosurg Psychiatry 2002;73:1-7

\section{Authors' affiliations}

T Umapathi, Department of Neurology, National Neuroscience Institute, Singapore V Chaudhry, D Cornblath, D Drachman, J Griffin, R Kuncl, Department of Neurology, Johns Hopkins University School of Medicine, Baltimore, USA

D Drachman, J Griffin, Department of Neuroscience, Johns Hopkins University School of Medicine, Baltimore, USA

J Griffin, R Kuncl, Department of Pathology, Johns Hopkins University School of Medicine, Baltimore, USA

The second to sixth authors contributed equally to this work.

Correspondence to: Dr T Umapathi, Department of Neurology, National Neuroscience Institute, Singapore 308433; tumapathi@yahoo.com

\section{REFERENCES}

1 Lange DJ, Fetell MR, Lovelace RE, et al. The floppy head syndrome. Ann Neurol 1986;20:133.

2 Katz JS, Wolfe GI, Burns DK, et al. Isolated neck extensor myopathy: a common cause of dropped head syndrome [comments]. Neurology 1996;46:917-21.

3 Brumback RA, Borge AF, Leech RW. Postpoliomyelitis amyotrophy with rod (nemaline) bodies in skeletal muscle. Transactions of the American Neurological Association 1980;105:430-1.

4 Hoffman D, Gutmann L. The dropped head syndrome with chronic inflammatory demyelinating polyneuropathy. Muscle Nerve 1994; 17:808-10.

5 Lomen-Hoerth C, Simmons ML, Dearmond SJ, et al. Adult-onset nemaline myopathy: another cause of dropped head. Muscle Nerve 1999;22:1146-50. 
6 Maruyama T, Hanyu N, Maruyama K, et al. Clinical and pathological studies on two patients with adult-onset nemaline myopathy. Rinsho Shinkeigaku 1990;30:738-44.

7 Rose MR, Levin KH, Griggs RC. The dropped head plus syndrome: quantitation of response to corticosteroids. Muscle Nerve 1999;22: 115-8

8 Karpati G, Carpenter S, Engel AG, et al. The syndrome of systemic carnitine deficiency. Clinical, morphologic, biochemical, and pathophysiologic features. Neurology 1975;25: 16-24.

9 Riggs JE, Bodensteiner JB, Schochet SS Jr. The dropped head sign: an unusual presentation of congenital myopathy. J Child Neurol 1994;9:330-1

10 Askmark H, Olsson Y, Rossitti S. Treatable dropped head syndrome in hypothyroidism [process citation]. Neurology 2000;55:896-7.

11 Bleck TP. Dropped head syndrome. Neurology 1992;43:846.

12 Quinn N. Disproportionate antecollis in multiple system atrophy [letter]. Lancet 1989;i:844.

13 Rivest J, Quinn N, Marsden CD. Dystonia in Parkinson's disease, multiple system atrophy, and progressive supranuclear palsy. Neurology 1990:40:1571-8.

14 Yoshiyama Y, Takama J, Hattori T. The dropped head sign in parkinsonism. I Neurol Sci 1999;167:22-5.

15 Askmark $\mathbf{H}$, Eeg-Olofsson KE, Johansson A, et al. Parkinsonism and neck extensor myopathy: a new syndrome or coincidental findings? Arch Neurol 2001;58:232-7.

16 Karbowski K. The old and the new camptocormia. Spine 1999;24:1494-8.

17 Gowers W. A manual of diseases of the nervous system. Classics of neurology and neurosurgery library. Birmingham, AL: Gryphon Editions, 1983:350-77.

18 Kuncl RW, Cornblath DR, Griffin JW Assessment of thoracic paraspinal muscles in the diagnosis of ALS. Muscle Nerve 1988; 11:484-92.

19 Hund E, Heckl R, Goebel HH, et al. Inclusion body myositis presenting with isolated erector spinae paresis. Neurology 1995;45:993-4.

20 Carpenter S, Karpati,G. Adult onset nemaline myopathy. Pathology of skeletal muscle. 2nd ed. New York: Oxford University Press, 2001:474.

21 Dialdetti R, Mosberg-Galili R, Sroka H, et al. Camptocormia (bent spine) in patients with Parkinson's disease: characterization and possible pathogenesis of an unusual phenomenon. Mov Disord 1999;14:443-7.

22 Onuaguluchi G. Parkinsonism. London: Butterworths, 1964
23 Martin JP. Curvature of the spine in post-encephalitic parkinsonism. J Neurol Neurosurg Psychiatry 1965;28:395-400.

24 Goldfarb LG, Gajdusek DC. Viliuisk encephalomyelitis in the lakut people of Siberia. Brain 1992;115:961-78.

25 Kiuru S, livanainen M. Camptocormia, a new side effect of sodium valproate. Epilepsy Res 1987; 1:254-7.

26 Gellido CL, Verghese J, Bieri PL, et al Very-late onset myasthenia gravis. AAEM Annual Meeting, 2000. Philadelphia: AAEM, 2000: 144

27 Guillain G, Mathieu P, Bertrand I. Etude anatomo-clinique sudeux cas d'atrophie olivo-ponto-cerebelleuse avec rigidite. Ann Med 1926;20:417-59.

28 Borit A, Rubinstein L, Urich H. The striatonigral degenerations: putamina pigments and nosology. Brain 1975;98:101-12.

29 Neumann MA. Pontocerebellar atrophy combined with vestibular-reticular degeneration. J Neuropathol Exp Neurol 1977;36:321-37.

30 Okamiya S, Ito $H$, Saito $T$, et al. A case of isolated neck extensor myopathy with parkinsonism. Rinsho Shinkeigaku 1997;37:393-6.

31 Suarez GA, Kelly JJ Jr. The dropped head syndrome [comments]. Neurology 1992;42: 1625-7

32 Jaster JH, Bertorini TE, Swims MP, et al. Cervical kyphosis after resolution of myopathic head drop. A case report. Spine 1996;21:2023-5.

33 Lerman VJ. Dropped head syndrome [letter; comment, discussion]. Neurology 1993:43:846-7.

34 Khella S, Frederic M. Dropped head syndrome [letter; comment, discussion]. Neurology 1993;43:846-7.

35 Wallgren-Pettersson C, Laing N. 40th ENMC Sponsored International Workshop: Nemaline Myopathy. February 1996 Naarden, The Netherlands. Neuromuscul Disord 1996;6:389-91.

36 Serratrice G, Pouget J, Pellissier JF. Bent spine syndrome. J Neurol Neurosurg Psychiatry 1996;60:51-4.

37 Martin JP. Old photographs: postencephalitic parkinsonism in two small boys. J Neurol Neurosurg Psychiatry 1983;46:953-5.

38 Ferrier $\mathbf{D}$. The functions of the brain. London: Smith, 1876.

39 Delmas-Marsalet P. Contribution experiment: Functions du Noyau caude. Bordeaux: 1925.

40 Hassler R. Die zentralen Apparate der Wendel. Arch Psychiat Nervenkr 1876;194:481-516.
41 Martin JP. The globus pallidus in post-encephalitic parkinsonism. J Neurol Sci $1965 ; 2: 344-65$

42 Alvarez-Gomez MJ, Vaamonde J, Narbona $J$, et al. Parkinsonian syndrome in childhood after sodium valproate administration. Clin Neuropharmacol 1993;16:451-5.

43 Sasso E, Delsoldato S, Negrotti A, et al. Reversible valproate-induced extrapyramidal disorders. Epilepsia 1994;35:391-3.

44 Delisle MB, Laroche M, Dupont H, et al. Morphological analyses of paraspinal muscles: comparison of progressive lumbar kyphosis (camptocormia) and narrowing of lumbar canal by disc protrusions. Neuromuscul Disord 1993:3:579-82.

45 Penisson-Besnier I, Menef P, Dubas F, et al. Histologic demonstartion of paravertebral muscle denervation in a pteinet with reducible lumbar kyphosis (camptocormia). Revue Du Rhumatisme, English edition, Paris 1994:61:868-70.

46 Laroche M, Delisle MB, Aziza R, et al. Is camptocormia a primary muscular disease? Spine 1995;20:1011-6.

47 Ehrenstein MR, Stoll T, Edwards JC. Not all stoops are due to osteoporosis [comments]. Ann Rheum Dis 1996:55:21-3.

48 Hilliquin P, Menkes CJ, Laoussadi S, et al. Camptocormia in the elderly. A new entity by paravertebral muscle involvement? Revue Du Rhumatisme 1992;59:169-75.

49 Poullin P, Daumen-Legre V, Serratrice G Camptocormia in the elderly patient: myopathy or muscular dystonia? Rev Rhum Ed Fr 1993;60:159-61.

50 Alnaqeeb MA, Al Zaid NS, Goldspink G. Connective tissue changes and physical properties of developing and ageing skeletal muscle. J Anat 1984;139:677-89.

51 Wharton SB, Chan KK, Pickard JD, et al. Paravertebral muscles in disease of the cervical spine. J Neurol Neurosurg Psychiatry 1996:61:461-5.

52 Lacomis D, Chad DA, Smith TW. Myopathy in the elderly: evaluation of the histopathologic spectrum and the accuracy of clinical diagnosis. Neurology 1993:43:825-8

53 Braun V, Mayer M, Antoniadis G, et al. Reconstruction of the spinal accessory nerve with an anastomosis to the dorsal C3 branch: technical note. Neurosurgery 1996:38:208-10.

54 England JD, Sumner AJ. Neuralgic amyotrophy: an increasingly diverse entity. Muscle Nerve 1987;10:60-8.

55 Stewart JD. Brachial plexus. Focal periphera neuropathies. Philadelphia, 2000: 142-3.

56 Kidron D, Barron SA, Mazliah J. Mononeuritis multiplex with brachial plexus neuropathy coincident with Mycoplasma pneumoniae infection. Eur Neurol 1989;29:90-2. 


\section{CORRESPONDENCE}

\section{Measuring carotid stenosis}

Comparing a new test with a standard involves measuring disagreement. In the case of measuring carotid artery stenosis, some of the disagreement between different tests is because of inherent differences in how the stenosis is demonstrated (test characteristics). This is what we are most interested in when assessing a new technology. However, some of the disagreement simply reflects variability in how we physically make the measurement with the standard technique. Choosing the point of maximum stenosis, choosing the point in the common carotid artery for use as a denominator, measuring from an eyepiece, or measuring from calipers all introduce variation when measuring carotid stenosis. The resulting observer variability in reporting contributes to disagreement between methods but to some extent is independent of the method used to generate the angiogram in the first place.

In the medical literature, disagreement between methods is often attributed entirely to test characteristics, with little appreciation of the role of observer variability in reporting. When one method is compared with anothe and disagreements emerge, it is not readily apparent how much of the disagreement is caused by the method used and how much by the process of measurement, unless observe variability data are also presented. In the recent paper from Patel et al, interobserver variability data are presented but their significance in relation to overall agreement does not appear to have been appreciated.

Using the data from Patel et al (tables 2 and 4) for symptomatic carotid arteries, it is noted that when 34 carotid digital subtraction angiograms (DSA) are measured by one radiologist, there was disagreement in seven cases when the same films were reported by a second radiologist. Therefore if only DSA was used, seven patients would have had "inappropriate" surgery according to which radiologist read the angiogram. This is no surprising, and such disagreement is a consistent finding in observer variability studies. $^{23}$ Observer variability in reporting DSA therefore accounted for approximately $20 \%$ of disagreement in this particular series of angiograms. This sets a limit on the maximum agreement that any alternative method can demonstrate when compared with DSA. It is clearly not reasonable to expect better agreement from another method than can be obtained by re-reporting the DSAs themselves. In Patel's table 2, when the same arteries are assessed by computed tomographic angiography (CTA) there was disagreement with DSA in seven cases, while with magnetic resonance angiography (MRA) and ultrasound there was disagreement in six and seven cases, respectively. The three alternatives thus disagree with DSA to the same extent as can be attributed to observer disagreement in reporting DSA. Put simply, the same number of missed or unnecessary operations would have occurred (roughly 20\% in this series) whatever method was used, including DSA alone. Observer variability is not confined to DSA, and the scatter plots from Patel et al (fig 2) would suggest-in keeping with other studies-that observer variability is greater for MRA and CTA than for DSA. ${ }^{1}$ It is surprising that this did not translate into more clinically important disagreements when MRA and CTA were compared with DSA. This is probably accounted for by the fact that in this study, for MRA and CTA, consensus views were taken for any disagreements greater than $10 \%$ between observers.

This highlights the important point that combining multiple observations made on the same data will reduce observer variability, and ultimately improve agreement with other methods. Partly for this reason, but also because to some extent the strengths and weaknesses of CTA, MRA, and duplex ultrasound are complementary, we would suggest that a combination of tests (we use the combination of ultrasound and MRA) should be used in preference to DSA.

What is clear from this study is that most of the disagreement between the different methods of measuring carotid stenosis can be attributed to observer variability in reporting rather than to the test characteristics of the individual methods themselves. The $10 \%$ of patients injured as a result of DSA in this study, and those who continue to be put at risk from catheter angiography in these circumstances, would be quite entitled to ask why they are exposed to a procedure which appears to offer no great advantage over safer alternatives. We suggest that more studies are not required, simply a more thorough understanding of presently available information.

G Young

Middlesbrough General Hospital, Ayresome Green Lane, Middlesbrough TS5 5AZ, UK

P Humphrey

The Walton Centre, NHS Trust, Liverpool, UK

Correspondence to: Dr G Young; gavin.young@stees.nhs.uk

\section{References}

1 Patel SG, Collie DA, Wardlaw JM, et al. Outcome, observer reliability, and patient preferences if CTA, MRA, or Doppler ultrasound were used, individually or together instead of digital subtraction angiography before carotid endarterectomy. J Neurol Neurosurg Psychiatry 2002;73:21-8.

2 Rothwell PM, Gibson RJ, Slattery J, et al. Prognostic value and reproducibility of measurements of carotid stenosis. A comparison of three methods on 1001 angiograms. European Carotid Surgery Trialists' Collaborative. Stroke 1994;25:2440-4

3 Young GR, Sandercock PA, Slattery J, et al Observer variation in the interpretation of intra-arterial angiograms and the risk of inappropriate decisions about carotid endarterectomy. I Neurol Neurosurg Psychiatry 1996;60:152-7.

\section{Author's reply}

Doctors Young and Humphrey highlight that differences between tests arise from several factors, some of which are inherent in the test and some of which arise from aspects attributable to observer variation. Some of the aspects to do with observer variation apply to interpretation of all tests and some are specific to certain tests. In our study we were endeavouring to quantify the effect on patient management if non-invasive tests were used instead of intra-arterial angiography to assess carotid stenosis. Our study has several limitations, including a relatively small sample size, and the fact that we were not able to get all scans read by all observers but rather had to get pairs of observers to concentrate on reading only CTA, or MRA, or DSA. A better design would have been to keep the same workers together in pairs but randomly assign the CTA, MRA, or DSA films to each pair. As it is, it is possible that some of the apparent difference between imaging modalities is specific to the pair of observers, not to the modality. However, imaging studies are difficult to fund and expensive to do, and the result and design of our study was a compromise involving all these factors.

We identified that the observer reliability of CT angiography or MR angiography was worse than that for digital subtraction angiography, as highlighted by Drs Young and Humphrey. Also in general there was more scatter between the observers for the reading of asymptomatic stenoses than for symptomatic stenoses (emphasising the importance of considering patient characteristics, not just the imaging technique). In the determination of the effect that this disagreement might have on patient management, we used nomograms derived from the European carotid surgery trial which were based on intra-arterial angiographic measurement of stenosis. We therefore had to use the comparison of non-invasive test reading with DSA rather than being able to use the individual observers readings of non-invasive tests. Thus as Drs Young and Humphrey point out, the actual effect of using non-invasive tests maybe worse than we have estimated.

Finally, Drs Young and Humphrey suggest that more studies are not required but we are not entirely sure that that is completely true. Non-invasive imaging tests are continually undergoing modifications, many of which may be improvements in accuracy or practicality, but this cannot be assumed to be the case. Much of this tinkering with technology is driven by the manufacturer's desire to encourage purchase of new machines. Improvements have also occurred in intraarterial angiography with smaller and more manoeuvrable catheters and greater awareness of the risks, which may have helped to reduce the risk of angiography. Our "snap shot" of CTA, MRA, and ultrasound is already out of date because contrast MRA is now increasingly used. While we would hope that non-invasive tests (probably in combination rather than alone) would eventually replace intra-arterial angiography in the majority of patients being considered for carotid intervention, we feel it likely that there will always be a need for some intra-arterial angiography in specific cases, or depending on local resources. In any case DSA did not appear less popular than MRA among the patients in our study. There is certainly room for much more in depth examination of existing data but we shouldn't close the door on the need for further studies. 


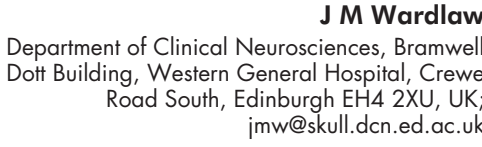

\section{Cerebral metastasis after primary renal cell carcinoma}

The article by Roser et al, ${ }^{1}$ in which it was shown that the treatment of intracranial metastases originating from renal cell carcinoma can on occasion be successful, was most interesting.

We have followed the clinical course of a patient with a renal cell carcinoma with a low mitotic index since 1989. In this patient the course was distinctly more malignant but the disease has also been successfully treated to date. In the last 13 years, this patient has had four metastases surgically removed and a further nine treated with stereotactically guided percutaneous single dose convergent beam irradiation therapy (stereotactic modified linear accelerator, 6-15 MV photons, 18-20 Gy prescribed to the $80 \%$ isodose). Apart from slight mnemonic deficits, the patient is in good health

The following factors which affect the prognosis $^{2-4}$ were all met by our patient

- The interval between the diagnosis of renal cell carcinoma and the first detected brain metastasis exceeds 17 months (our patient, 18 months; the patient described by Roser et al, ${ }^{1} 36$ months);

- Age below 60 years at the time of initial diagnosis;

- Primary tumour of the left kidney, initial nephrectomy;

- Diameter of primary metastasis $<2 \mathrm{~cm}$;

- Not more than one brain metastasis at the time of initial treatment;

- Solely intracranial metastases;

- Karnofsky > 70\%;

- No systemic symptoms such as fever or weight loss at the time of diagnosis;

- Blood sedimentation rate under $50 \mathrm{~mm} / \mathrm{h}$ at diagnosis of renal cell carcinoma.

Patients in whom prognostic factors predict a good outcome should be treated with intent to cure.

S Heckl

Department of Neuroradiology, University of Heidelberg Medical School, Kopfklinik, Im Nevenheimer Feld 400, 69120 Heidelberg,

Germany

K Braun, J Debus

Department of Radiation Oncology, German Cancer Research Centre, Heidelberg

S Kunze

Department of Neurosurgery, University of

Heidelberg

Correspondence to: Dr med Stefan Heckl s.heckl@dkfz-heidelberg.de

\section{References}

1 Roser F, Rosahl SK, Samii M. Single cerebral metastasis 3 and 19 years after primary renal cell carcinoma: case report and review of the literature. J Neurol Neurosurg Psychiatry 2002;72:257-8.

2 Decker DA, Decker VL, Herskovic A, et al. Brain metastases in patients with renal cell carcinoma, prognosis and treatment. J Clin Oncol 1984;2: 169-73.
3 Wronski MD, Maor MH, Davis BJ, et al. External radiation of brain metastases from renal carcinoma: a retrospective study of 119 patients from the M D Anderson Cancer Center. Int J Radiat Oncol Biol Phys 1997:37:753-9.

4 Culine S, Bekradda M, Kramar A, et al. Prognostic factors for survival in patients with brain metastases from renal cell carcinoma. Cancer 1998;83:2548-53.

\section{BOOK REVIEWS}

\section{Seizures, medical causes and management}

Edited by Norman Delanty (Pp 352 US\$1 25.00). Published by the Humana Press New Jersey, 2002. ISBN 0-89603-827-0

This book is unusual among books about seizures because it focuses on acute symptomatic ("situation-related") seizures, rather than "epilepsy" (although there is inevitably some overlap between the two). It provides definitions and describes the epidemiology and pathophysiology of acute symptomatic seizures in the initial section, which is followed by chapters detailing the specific circumstances in which such seizures are likely to occur, often (although not invariably) including points of management specific to the situation. Subjects covered include seizures occurring in the context of multisystem disease, infection, hypoxic-ischaemic cardiopulmonary conditions, endocrine disorders, cancer and other conditions. Situation-related seizures occurring as a result of drugs or alcohol misuse are also addressed, as are those occurring in the intensive care situation, and the difficult, but important, differentiation of seizures from syncope. The book ends with a very practical chapter entitled "Anticonvulsants in acute medical illness", in which the considerations affecting the choice of antiepileptic drug in the acute situation are reviewed.

Although situation-related seizures are usually discussed in books about epilepsy, they do appear to constitute a distinct group in a number of respects including prognosis. To a certain extent the topics discussed in the book form a rather disparate group linked only by their tendency to cause such seizures as a reflection of central nervous system disturbance. Nevertheless, they are all conditions likely to be encountered at various times by general physicians, neurologists, and those working in the accident and emergency department, and this book, which is both readable and comprehensively referenced, will be of interest to all these groups.

Yvonne Hart

\section{Subcortical stroke, 2nd edition}

Edited by Geoffrey Donnan, Bo Norrving, John Bamford, and Julien Bogousslavsky (Pp 450, £79.50). Published by Oxford University Press, New York, 2002. ISBN 0-19-263-157-8

This book is a must read for clinicians and researchers with an interest in stroke. The four editors are all specialist stroke clinicians who have been thinking about and leading research in subcortical stroke for many years, and they have put together a well constructed and comprehensive multiauthor work. This second edition is longer and more extensive than the first, reflecting the considerable and rapid advances in our understanding of subcortical strokes in recent years, and in particular the increasingly sophisticated neuroimaging techniques. Given the large number of contributors, consistency of style and approach is limited, but this is more than made up for by the breadth of expertise and opinion.

There are some particular strengths. These include the editors' short chapter providing a summary classification of subcortical infarcts, which is best appreciated if read both before and after tackling most of the other chapters. The excellent chapter on pathology of lacunar infarction is a welcome addition to this edition, while the chapters discussing risk factors and prognosis provide very useful commentaries and summary tables of all the relevant studies. The discussion around the usefulness (or not) of clinical diagnosis of lacunar syndromes, carefully updated with the information from recent clinicoradiological studies, is both thoughtful and logical, with plenty of clinical and epidemiological common sense.

In common with all recently published medical textbooks, this one is already a little out of date. This is most noticeable for the chapter on therapy, where recent advances (for example, new evidence on blood pressure lowering from the PROGRESS trial and on cholesterol reduction with a statin from the Heart Protection Study) are likely to have most impact on clinical practice. If the editors have the energy to produce a third edition, there is (as always) some room for improvement. The series of chapters on infarcts in specific subcortical territories would be enhanced by some figures illustrating the vascular anatomy that is discussed in the text. In addition, the quality of the discussion of study methodology varies considerably between chapters, and some would benefit from a more systematic and accurate approach to statistical and epidemiological concepts.

Cathie Sudlow

\section{Medical risks in epilepsy}

Edited by Svein I Johannessen, Torbjörn Tomson, Matti Sillanpää, and Birthe Pedersen (Pp 140, £29). Published by Wrightson Biomedical Publishing Ltd, Hampshire, 2002. ISBN 1- 871816-46-7

This is a very useful, reasonably comprehensive yet succinct multiauthor small book on medical risks associated with epilepsy. Areas covered include methodological aspects; accidents and risks in everyday life; traffic accidents; driving regulations; mortality, including SUDEP; psychiatric comorbidity and suicide; fatal adverse drug reactions reporting data (which are rather difficult to interpret); seizure-warning systems and risk prevention; as well as insurance related issues. It also highlights many areas where further research is required. The book generally provides an overview of the more recent research and publications in this area and includes some regulatory issues. Inevitably it has a Nordic emphasis; it includes very useful advice on precautionary measures to minimise risk of injury for people with uncontrolled epilepsy, including safer sauna. Some chapters, by necessity, serve purely as a compilation of available incomplete data. Others are written by key researchers directly involved in the area addressed and provide a very balanced review of current knowledge. On psychiatric comorbidity, while agreeing that "the positive 
effects of drug therapy on cognitive and affective functioning because of the reduction in seizure activity are usually far greater than the negative effects", more information would have been welcome in an otherwise very well balanced chapter. The book would well serve those for whom it is intended, namely epileptologists, neurologists, paediatric neurologists, psychiatrists, and other professionals who deal with patients with epilepsy. The editors rightly stress the "official line" that the majority of patients with epilepsy can achieve good control, with low associated risks.

Lina Nashef

\section{Greenfield's neuropathology, 7th edition}

Edited by David I Graham and Peter L Lantos. (2 Vol set (HB), Vol 1 ppl 190, Vol 2 ppl 140 $£ 395)$. Published by Arnold, London, 2002. ISBN 0-340-74231-3. CD rom (£145) ISBN 0-340-76-221-7.

What can one say. The latest (7th) edition of Greenfield's Neuropathology has hit the bookshops, and indeed what a resounding thud it makes! The present edition is bigger than ever, again running into two volumes, but now totalling a staggering 2330 pages and costing an equally staggering $£ 395$. It comes equipped with a handy $C D$ version of the illustrations, a mere snip at $£ 145$.

The 7th edition has undergone considerable changes in content, since the last edition five years ago, reflecting the ever expanding increase in knowledge of diseases of the nervous system and muscle that has come from the exponential growth in neuroscience research over the past decade. Areas of cellular and molecular neurobiology, and the contributions that genetics and neuroimaging have made towards improving our understanding of the causes of disease and our clinical investigative and diagnostic skills, are more strongly featured. Hence, while greater emphasis has been placed on the basic science of disease, the classic descriptive morphology for which Greenfield's is renown is well maintained. There are new chapters on "Metabolic and neurodegenerative diseases of childhood" and "Peroxisomal and mitochondrial diseases". The chapter on "Pathology of schizophrenia" has been shrewdly expanded to cover "The pathology of psychiatric disorders". Other chapters have been retained as such, but many have been rewritten with new authors reflecting the pre-eminence of each within their particular subspecialty. There is increased reliance on colour illustrations, line diagrams and tables to illuminate the text and these are of excellent quality throughout. As to be expected, all chapters are written authoritatively with clarity and style, comprehensively illustrated, and lavishly referenced. Judging by the content of the chapters on ageing and dementia, prion disease, and movement disorders, it is my guess that if anything is not included in each chapter, it's probably not worth including anyway. The accompanying $\mathrm{CD}$ rom is user friendly, and the images are downloadable - $\mathrm{a}$ boon to those wishing to produce a ready made lecture or presentation of distinction. The book is a must for practicing and trainee pathologists, but is equally compelling for workers in other clinical neuroscience disciplines and basic researchers interested in the roots of the dysfunctional nervous system. Possession of the 7th edition is guaranteed lasting quality and full value, but before lashing out make sure both your arms and shelving are strong enough to accommodate its presence.

David MA Mann

\section{Smell and taste complaints}

Edited by Christopher H Hawkes (Pp 176, £16.99). Published by ButterworthHeinemann, Woburn, 2002. ISBN 0-75067287-0.

Despite the fact that problems with tasting and smelling are common in the general population, few physicians have the knowledge and training to authoritatively deal with them. Christopher Hawke's Smell and Taste Complaints provides a straightforward guide to the understanding and management of chemosensory disturbances, reflecting the first clinically oriented book of its kind since Ellis Douek's The Sense of Smell and its Abnormalities (Edinburgh: Churchill Livingstone, 1974). This 180 page pocket sized book provides a cogent overview of the anatomy and physiology of the olfactory and gustatory systems, practical approaches towards their assessment, and suggestions for therapy and management. Importantly, it provides the practitioner with the names and addresses of specialised taste and smell clinics throughout the world, aiding the referral process. Although there is little new in this guide, and much of the material seems to have been derived from second hand sources, it presents the available information in a well organised and easy to read manner. Moreover, it addresses basic clinical issues rarely addressed in a single publication. Its major drawback is the lack of reference backing for many of its statements, some of which are questionable. I found, for example, some of the "facts" unfamiliar, and would have welcomed knowledge of their source. Bits of the material are dated (for example, the role of $\mathrm{IP}_{3}$ receptors in olfactory function, the nature of olfactory receptor cell regeneration) and several sections of the book seem lengthy, uncritical, and of little practical value. Thus, nearly seven pages are devoted to the topic of odour memory, a topic with inherent theoretical issues and problems that are not addressed by the author. However, the book is not intended to be a research book and, despite such shortcomings, it accomplishes its goal of educating the practitioner and providing him or her with a practical roadmap for clinical assessment and treatment. Indeed, the clinical information provided is comprehensive and well illustrated. This inexpensive book is a must for any physician who has the occasion to see patients with chemosensory disturbances or has even a casual interest in chemosensation, and should serve to elevate the level of appreciation of these senses within the medical community at large.

Richard L Doty

\section{CORRECTIONS}

The following errors occurred in the short report by Merlini L, Carbone I, Capanni C, et al. Familial isolated hyperCKaemia associated with a new mutation in the caveolin-3 (CAV-3) gene. J Neurol Neurosurg Psychiatry 2002;73:65-7. On page 66, left column, line 9, proline should replace leucine, line 12, protein should replace enzyme, and in table 1 , line 8 Del-TFT (63-65) should replace ?TFT (63-65).

We regret that an editing error occurred in the correspondence from Jaster JH, Dohan FC, and $\mathrm{O}^{\prime}$ Brien TF. Demyelination in the brain as a paraneoplastic disorder: candidates include some cases of seminoma and central nervous system lymphoma. J Neurol Neurosurg Psychiatry 2002;73;352. The description of a patient was altered, in the first line of the fourth paragraph the text should read "... patient who had a non-neurological malignancy, seminoma, and subsequently developed a paraneoplastic syndrome ...". 